\title{
Hansfordia pulvinata Hyperparasiting Passalora fulva on Organic Tomato Plants
}

\author{
Mi-Jeong Park ${ }^{1}$, Jae-Gu Han ${ }^{1}$, Ju-Hee Kim² and Hyeon-Dong Shin ${ }^{1 *}$ \\ ${ }^{1}$ Division of Environmental Science and Ecological Engineering, Korea University, Seoul 136-701, Korea \\ ${ }^{2}$ Jeollabuk-do Agricultural Research and Extension Services, Iksan 570-704, Korea
}

(Received on April 7, 2010; Accepted on July 28, 2010)

Tomato (Solanum lycopersicum L.) is one of the most commonly used vegetables worldwide. The production of organic tomatoes, grown without using any chemicals, has continuously increased in Korea since consumers started to demand organic foods. In organic tomato greenhouses in Iksan and Jeonju, Korea, a change was observed in a tomato leaf mold (Passalora fulva, syn. Fulvia fulva) in spring, 2009. The dark brown lesions of this mold changed into white to pale grayish ones, by growth of an overgrowing fungus (Fig. 1A). On some old leaves, the leaf mold lesions were largely destroyed and covered with the white fungus (Fig. $1 \mathrm{~B} \& \mathrm{C}$ ). It was also observed that young colonies of leaf mold were suppressed by the white fungus, and further expansion of the lesions was arrested.

The overgrowing white fungus was microscopically examined from representative samples, which are housed at Korea University (KUS-F24001, F24017). Conidiophores were erect, straight, smooth, variable in length, reaching up to $500 \mu \mathrm{m}, 2-4 \mu \mathrm{m}$ wide, branched repeatedly at the upper part, pale olivaceous brown (Fig. 1D). Conidiogenous cells were integrated, terminal, cylindrical, subhyaline, denticulate, $7-15 \times 2-3.5 \mu \mathrm{m}$ (Fig. 1E \& F). Conidia were solitary, globose, smooth, aseptate, subhyaline, 4-6 $\mu \mathrm{m}$, with an
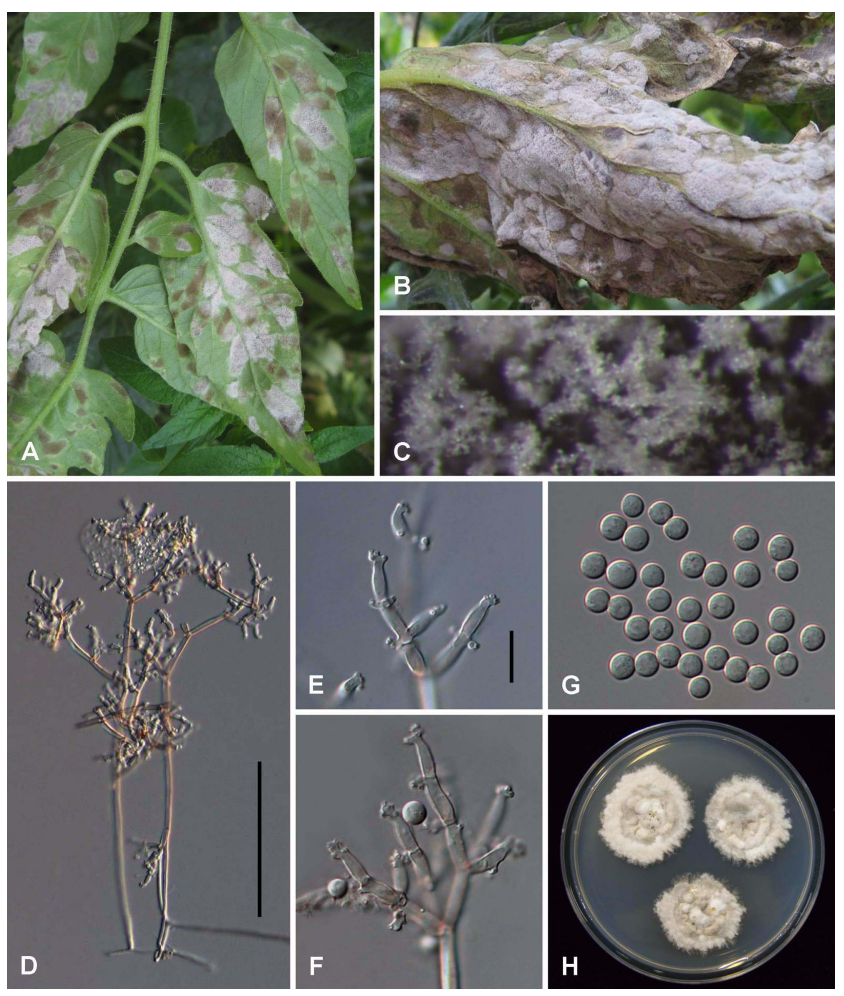

Fig. 1. A and B: Hansfordia pulvinata colonizing dark brown regions of Passalora fulva on young (A) and old tomato leaves (B). C: Close-up view of clusters of $H$. pulvinata. D: Conidiophores. $\mathbf{E}$ and $\mathbf{F}$ : Upper parts of conidiophores showing denticulate conidiogenous cells. G: Conidia. H: 5week-old culture of $H$. pulvinata growing on PDA. Bar $=100 \mu \mathrm{m}$ for D and $10 \mu \mathrm{m}$ for $\mathrm{E}-\mathrm{G}$. inconspicuous hilum (Fig. 1G). Based on these morphological characteristics, the fungus was identified as Hansfordia pulvinata (Berk. \& M. A. Curtis) S. Hughes (Saccardo, 1886).

To confirm the identity of the fungus, the ITS rDNA region of an isolate obtained from KUS-F24001 was amplified and sequenced. A resulting sequence of the isolate was deposited in GenBank (HM060587). A BLAST search indicated that the ITS sequence shared $98 \%$ similarity with a sequence of $H$. pulvinata (AY908993).

Monoconidial isolates of $H$. pulvinata were successfully cultured, forming velvety grayish colony with abundant conidia on PDA (Fig. 1H). The isolates were deposited in Korean Agricultural Culture Collection, Suwon, Korea (KACC44498 and 44502). A mycoparasitic test was carried out using detached leaves from 1month-old tomato plants infected with P. fulva. An inoculum (ca. $10^{5}$ conidia/ml) was prepared by harvesting conidia formed on 30-dayold cultures and sprayed on 10 leaves having the lesions of leafmold. Five leaves which served as control were sprayed with sterile distilled water. The typical growth of grayish colonies of $H$. pulvinata appeared on dark brown patches of the diseased leaves within 7 days after inoculation. The hyperparasitic fungus was reisolated from those lesions. No symptoms developed on control leaves.

H. pulvinata has been well known to have ability to infect several plant pathogens, viz. P. fulva on tomato plant leaves, Cercosporidium personatum on peanut plant leaves, and Fusicladium macrosporum on rubber tree leaves (Mello et al., 2008; Mitchell et al., 1987; Tirilly et al., 1983). The previous studies have shown the antifungal potential of $H$. pulvinata are such that the fungus can be used as a biocontrol agent (BCA) of plant diseases. This is the first report documenting the occurrence of the hyperparasite on organic tomatoes in Korea. Further studies are required to assess the biocontrol efficacy of the present isolates in the process of exploiting formulated BCA products.

\section{Acknowledgements}

This work was financially supported by research grants from the BioGreen 21 program (no. 20080401034028), Rural Development Administration, Korea.

\section{References}

Mello, S. C. M., Estevanato, C. E., Braúna, L. M., de Capdeville, G., Queiroz, P. R. and Lima, L. H. C. 2008. Antagonistic process of Dicyma pulvinata against Fusicladium macrosporum on rubber tree. Trop. Plant Pathol. 33:5-11.

Mitchell, J. K., Smith, D. H. and Taber, R. A. 1987. Potential for biological control of Cercosporidium personatum leafspot of peanuts by Dicyma pulvinata. Can. J. Bot. 65:2263-2269.

Saccardo, P. A. 1886. Sylloge Fungorum Omnium Hucusque Cognitorum. Vol. IV. Padova.

Tirilly, Y., Kloosterman, J., Sipma, G. and Kettenes van den Bosch, J. J. 1983. A fungitoxic sesquiterpene from Hansfordia pulvinata. Phytochemistry 22:2082-2083.

*Corresponding author (hdshin@korea.ac.kr) 